\title{
Lumbar Stenosis of the Aging Spine: Evaluation and Treatment According to the Evidence Based Medicine for the Improvement of the Quality of Life
}

\author{
Luca Collebrusco ${ }^{1,2^{*}}$, Luca Palmieri' ${ }^{3}$, Giovanna Censi ${ }^{4}$, Rita Lombardini ${ }^{5}$ \\ ${ }^{1}$ Research Department C.R.O.M.O.N., EDUCAM School, Rome, Italy \\ ${ }^{2}$ Rehabilitation Unit, National Health Service of Umbria, Perugia, Italy \\ ${ }^{3}$ Freelance Consultant, Perugia, Italy \\ ${ }^{4}$ INRCA University Polytechnic of Marche, Ancona, Italy \\ ${ }^{5}$ Departmen of Medicine, University of Perugia, Perugia, Italy \\ Email: ^luca.collebrusco@unipg.it
}

How to cite this paper: Collebrusco, L., Palmieri, L., Censi, G. and Lombardini, R. (2017) Lumbar Stenosis of the Aging Spine: Evaluation and Treatment According to the Evidence Based Medicine for the Improvement of the Quality of Life. Open Journal of Therapy and Rehabilitation, 5, 36-42. https://doi.org/10.4236/ojtr.2017.51004

Received: December 14, 2016

Accepted: February 12, 2017

Published: February 15, 2017

Copyright $\odot 2017$ by authors and Scientific Research Publishing Inc. This work is licensed under the Creative Commons Attribution International License (CC BY 4.0).

http://creativecommons.org/licenses/by/4.0/ c) (i) Open Access

\begin{abstract}
The lumbar spinal stenosis (LSS) is a syndrome with a wide economic and social impact on the adult population. It is a particular form of narrowing of the lumbar vertebral canal or the intervertebral foramina which can compress the neural and vascular elements in the lumbar spine. It is a degenerative process which predominantly affects the geriatric population. The increase of the life expectancy has increased the health needs of this target of population. The (LSS) is a syndrome that can manifest itself with lower back pain and pain to the inferior limbs, and functional disabilities which affects mobility and motor skills. Given the complexity of the clinical presentation, an accurate clinicalfunctional evaluation is needed that includes: The combination of clinical signs from the patient's history, a physical evaluation and diagnostic imaging, excluding possible red flags. In this respect, the use of Rehabilitative Ultrasound Imaging (RUSI) might be useful in the evaluation and treatment process, enhancing the effectiveness and documenting the benefits of it. The aim of this work is to propose an integrated evidence-based approach that may be useful for improving the quality of life of LSS patients.
\end{abstract}

\section{Keywords}

Physical Therapy, Lumbar Spinal Stenosis, Rehabilitative Ultrasound Imaging, Regional Interdependence, Rehabilitation 


\section{Introduction}

The lumbar spinal stenosis (LSS) is a syndrome with a wide economic and social impact on the adult population [1]. LSS is caused by a gradual narrowing of the spinal canal or the intervertebral foramina which can compress the neural and vascular elements in the lumbar spine [2] [3] [4]. It is a degenerative process with predominantly affects the geriatric populations. With an aging population and unsustainable healthcare costs, there is an associated rise in the prevalence of degenerative spinal disorders as LSS [5] [6]. The LSS syndrome can manifest itself with low back pain and pain to the inferior limbs, and functional disabilities which affects mobility and motor skills in the entire lower quadrant [7]. Given the complexity of the clinical presentation, an accurate clinical-functional evaluation is needed that includes: the combination of clinical signs from the patient's history, a physical evaluation and a diagnostic imaging, excluding possible red flags [8] [9] [10] [11] [12]. Currently, the intervention of surgical decompression, together with the epidural injection of steroids are considered natural treatment of the stenosis as reported by different publications [13]. Nevertheless, clinical experience has pointed out that many patients could also improve his/her own condition avoiding it. The purpose of this work is to analyze a range of evidence-based treatment options in order to identify an integrated conservative management that may improve quality of life by relieving pain in LSS patient.

\section{Integrated Conservative Management Hypothesis}

The range of evidence-based treatment options for LSS patients includes: several manual techniques that include both thrust and non-thrust manipulation/mobilization, therapeutic exercise, use of biofeedback known as RUSI, educational intervention to the patient and a program of walking re-education [14] [15], (Figure 1). This type of intervention guarantees low risks for the patient and is the first alternative to surgical treatment [16]. Furthermore, the essential concept underlying LSS management is that should be treated all body parts involved in walking i.e. the chest, pelvis, hips and lower limbs.

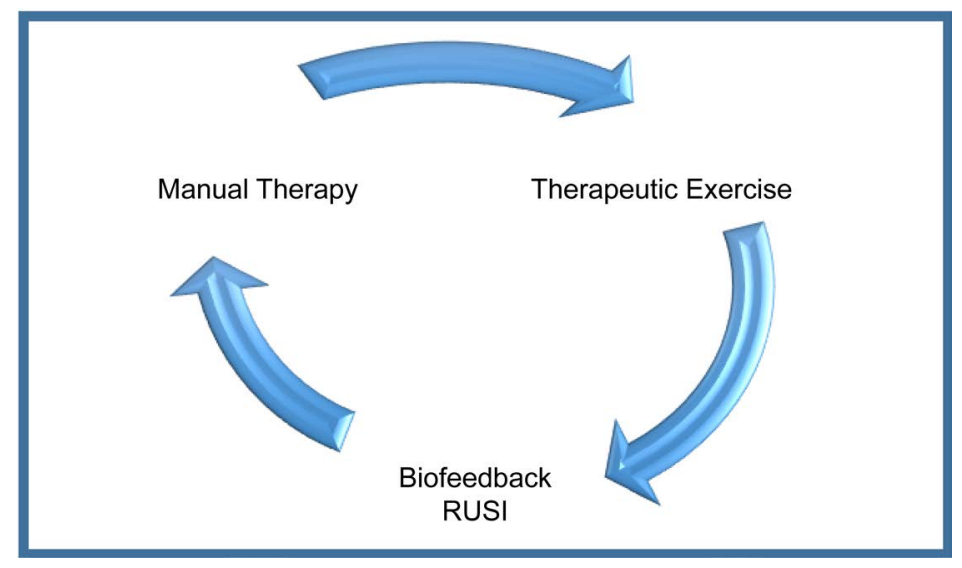

Figure 1. LSS integrated conservative management. 
Successful results were reported with manual techniques described as follows: flexion-distraction manipulations, sidelying lumbar rotation thrust, posteriorto-anterior mobilizations, sidelying translatoric side bending manipulations, thoracic thrusts, neural mobilizations (Figure 2).

The therapeutic exercise represents a relevant component of the treatment protocol of patients with LSS. Together manual therapy, the fundamental objective of therapeutic exercise prescription is to improve overall fitness and function through the increase of available cross-sectional area of the spinal canal, supporting vascular changes and self-management. The physiotherapist must have a cluster of exercises to use for specific patients. It may include exercises for the mobility of the lumbar spine and the hip, exercises of lumbar bending and rotation, spinal flexibility exercises recommended to the patients i.e. thoracic extension self-mobilization or stretching exercises and lumbar rotation exercise (Figure 3). Finally, exercises for muscles of the hips and the abdomen. In fact,
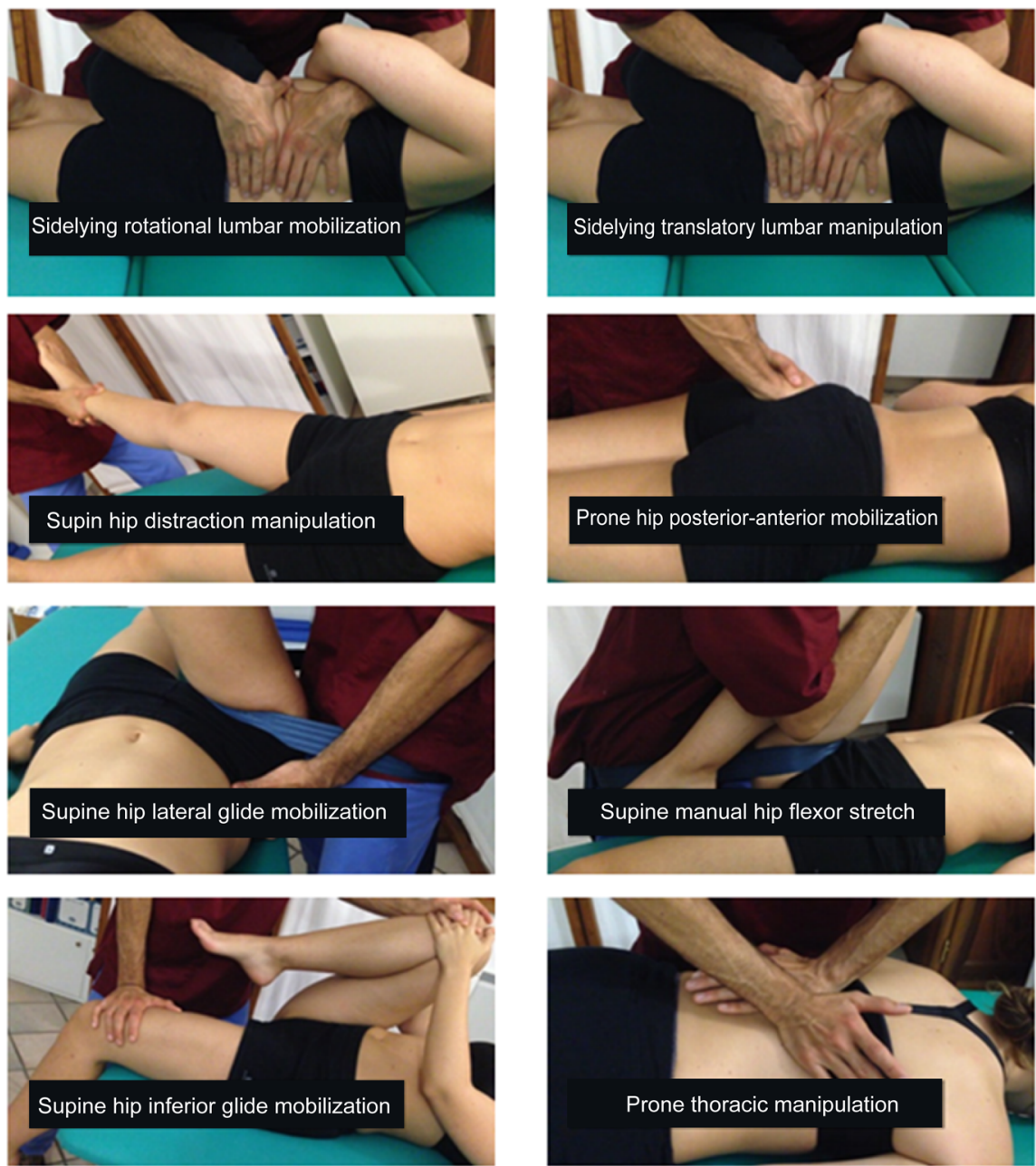

Timetable of Treatment Administration

- For six weeks

- Two times/week

- For twelve treatment sessions

- Promotion to walk three times to week

Figure 2. Manual therapy techniques for LSS. 
core strengthening/stabilization is one of the most useful treatment program for low back pain and it may benefit from the use of biofeedback.

The treatment with biofeedback is called RUSI (Figure 4). The use of RUSI in the clinical practice is recommended for understand the relationships between motor control and muscular functionality, to enhance the performance by increasing the feedback and to document the benefits of a specific therapeutic approach [17]. It includes a program of core strengthening/stabilization [18]. It is expected that core exercises will attempt to allow the patient to control pelvic position and motion to minimize symptoms while standing and walking. There are evidences in literature that a dysfunction of the transversus abdominis $(\operatorname{Tr} A)$

\begin{tabular}{|l|}
\hline Single Knee to chest \\
\hline Double Knee to chest \\
\hline Lumbar rotation stretch \\
\hline Thoracic extension self-mobilisation \\
\hline Rectus femoris self-stretch \\
\hline Iliopsoas self-stretch \\
\hline Lower abdominal strengthening exercise \\
\hline Hip abduction strengthening exercise \\
\hline
\end{tabular}

\section{Timetable of Treatment Administration}

\begin{tabular}{|c|}
\hline For eight weeks \\
\hline Two times/week \\
\hline For sixteen treatment sessions \\
\hline
\end{tabular}

Figure 3. Therapeutic exercise program.

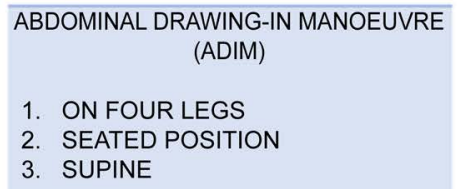

ACTIVE STRAIGHT-LEG RAISE

CONTROLATERAL ARM RAISE MANOEUVRE
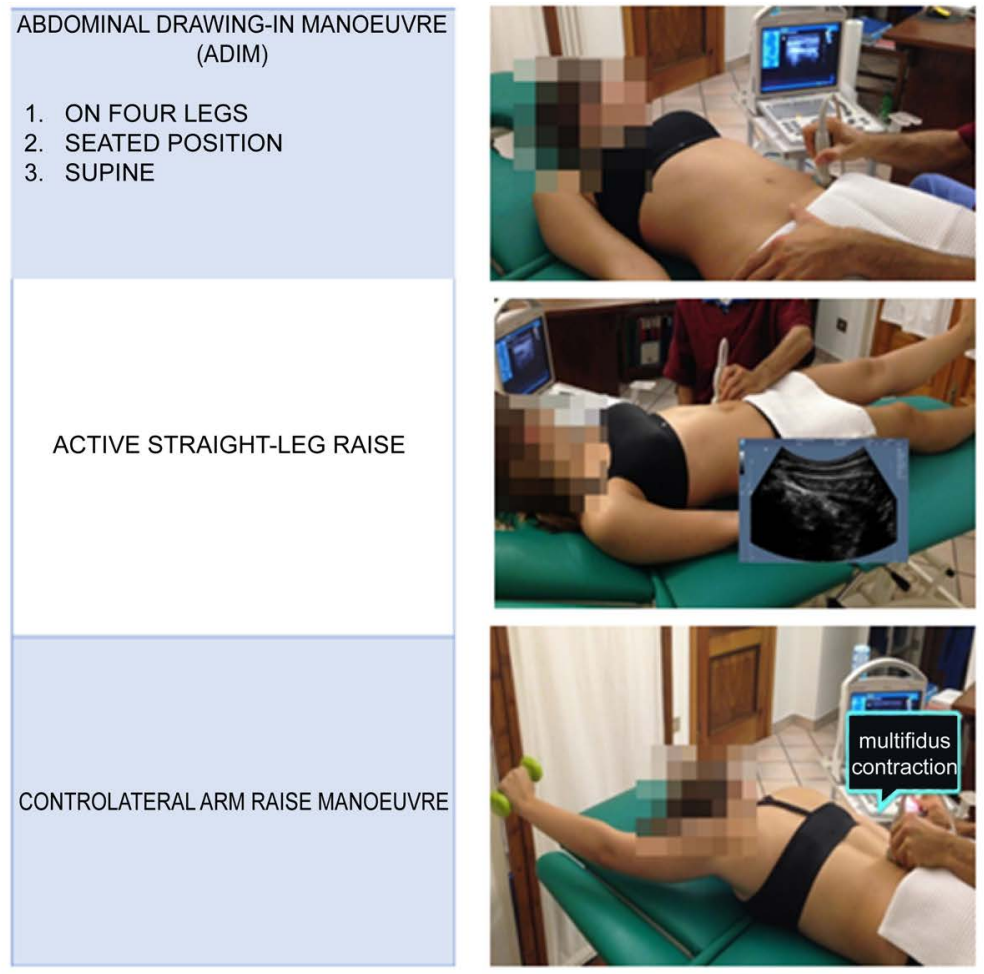

Timetable of Treatment Administration

- Two times/week for eight weeks

- For sixteen treatment sessions

- Each session lasts about forty minutes

Figure 4. Biofeedback (RUSI) protocol. 
and multifidus muscle (MF) both are the key of the impairment in the patients with low back pain because it would compromise the spines stability. The exercise used for the recruitment of transversus and multifidus (muscles involved in lumbar stabilization) are: Abdominal drawing-in maneuver, active straight-leg raise and contralateral arm raise maneuver [19] [20] [21]. Before beginning with the exercise, in addition to the instructions, the physiotherapist shows to the patient the action of the muscles involved through ultrasound imaging; the evidences report that 5 minutes of biofeedback is the correct time to optimize performance [22].

\section{Discussion}

Lumbar spine pain is characterized by the delayed contraction of the transversus muscle and lower increase of the muscular abdomen volume; the multifidus muscle shows similar functional deficits and morphological changes, all of this represents important clinical evidence [23]. The ultrasound imaging in rehabilitation, called RUSI, is defined as: "a procedure used by the physiotherapist to appraise the muscle and the relative morphology of the soft tissues and the functionality during the physical exercise and the activities". The RUSI is used as support to the application of therapeutic interventions finalized to improve the neuromuscular functionality. This helps to guarantee a feedback to both the patient and the physiotherapist for improving clinical outcomes. The high presence of anatomic lumbar spinal stenosis on imaging in asymptomatic older people makes this syndrome a complex condition to diagnose and treat. Many of the treatments lack strong evidences and, given the complexity and heterogeneity of the situation, an integrated and shared approach is needed [24].

\section{Conclusion}

According to the Evidence Based Medicine, the rehabilitative approach to LSS based on the integrated use of different techniques is that with a best evaluation of the results (Outcome) in terms of pain reduction and improvement of the quality of life. However, further studies are needed in order to validate the standardized diagnostic procedure and the rehabilitation program; keeping in mind that, in this context, a part of the treatment can also be performed with the aid of the RUSI, improving the performances and helping the physiotherapist job.

\section{Acknowledgements}

The authors would like to thank Alice Volpi for translating and editing this paper.

\section{References}

[1] Jackson, D.A. (1998) The History of and Clinical Findings in Lumbar Spinal Stenosis: A Brief Review. Physical Therapy Reviews, 3, 163-167.

https://doi.org/10.1179/ptr.1998.3.3.163

[2] Kalichman, L., Cole, R., Kim, D.H., et al. (2009) Spinal Stenosis Prevalence and As- 
sociation with Symptoms: The Framingham Study. The Spine Journal, 9, 545-550. https://doi.org/10.1016/j.spinee.2009.03.005

[3] Lurie, J. and Tomkins-Lane, C. (2016) Management of Lumbar Spinal Stenosis. $B M J, 352$, h6234.

[4] http://www.istat.it/it/anziani/popolazione-e-famiglie

[5] O’Lynnger, T.M., Zuckerman, S.L., Morone, P.J., et al. (2015) Trends for Spine Surgery for the Elderly: Implications for Access to Healthcare in North America. Neurosurgery, 77, S136-S141. https://doi.org/10.1227/NEU.0000000000000945

[6] Sizer, P., Brismee, J.M. and Cook, C. (2007) Medical Screening for Red Flags in the Diagnosis and Management of Musculoskeletal Spine Pain. Pain Practice, 7, 53-71. https://doi.org/10.1111/j.1533-2500.2007.00112.x

[7] Collebrusco, L., Lombardini, R. and Censi, G. (2016) Regional Interdependence: A Model That Needs to Be Integrated in the Functional Evaluation and Physiotherapy Treatment-Part1. Open Journal of Therapy and Rehabilitation, 4, 117-124. https://doi.org/10.4236/ojtr.2016.43010

[8] Delitto, A., George, S.Z., Van Dillen, L., Whitman, J.M., Sowa, G., Shekelle, P., Denninger, T.R., Godges, J.J., et al. (2012) Clinical Guidelines, Low Back Pain. Journal of Orthopaedic \& Sports Physical Therapy, 42, A1-A57. https://doi.org/10.2519/jospt.2012.42.4.A1

[9] Binder, D.K., Schmidt, M.H. and Weinstein, P.R. (2002) Lumbar Spinal Stenosis. Seminars in Neurology, 22, 157-166. https://doi.org/10.1055/s-2002-36539

[10] Boden, S.D., Davis, D.O., Dina, T.S., et al. (1990) Abnormal Magnetic-Resonance Scans of the Lumbar Spine in Asymptomatic Subjects. Journal of Bone and Joint Surgery, American Volume, 72, 1178-1184.

[11] Haig, A.J., Tong, H.C., Yamakawa, K.S., et al. (2005) The Sensitivity and Specificity of Electrodiagnostic Testing for the Clinical Syndrome of Lumbar Spinal Stenosis. Spine, 30, 2667-2676. https://doi.org/10.1097/01.brs.0000188400.11490.5f

[12] Bressler, H.B., Keyes, W.J., Rochon, P.A. and Badley, E. (1999) The Prevalence of Low Back Pain in the Elderly. A Systematic Review of the Literature. Spine, 24, 1813-1819. https://doi.org/10.1097/00007632-199909010-00011

[13] Zaina, F., Tomkins-Lane, C., Carragee, E. and Negrini, S. (2016) Surgical versus Non-Surgical Treatment for Lumbar Spinal Stenosis. Spine, 41, E857-E868. https://doi.org/10.1002/14651858.cd010264.pub2

[14] Backstrom, K.M., Whitman, J.M. and Flynn, T.W. (2011) Lumbar Spinal Stenosis-Diagnosis and Management of Aging Spine. Manual Therapy, 16, 308-317. https://doi.org/10.1016/j.math.2011.01.010

[15] Reiman, M.P., Harris, J.Y. and Cleland, J.A. (2009) Manual Therapy Interventions for Patients with Lumbar Spinal Stenosis: A Systematic Review. New Zealand Journal of Physiotherapy, 37, 17-28.

[16] Richardson, C.A., Hodges, P. and Hides, J.A. (2004) Therapeutic Exercise for Spinal Segmental Stabilization in Low Back Pain: Scientific Basis and Clinical Approach. 2nd Edition, Churchill Livingstone, Edinburgh.

[17] Worth, S., Henry, S.M. and Bunn, Y. (2007) Real Time Ultrasound Feedbak and Abdominal Hollowing Exercises for People with Back Pain. New Zealand Journal of Physiotherapy, 35, 4-11.

[18] Van, K., Hides, J.A. and Richardson, C.A. (2006) The Use of Real-Time Ultrasound Imaging for Biofeedback of Lumbar Multifidus Muscle Contraction in Healthy Subjects. Journal of Orthopaedic \& Sports Physical Therapy, 36, 920-925. https://doi.org/10.2519/jospt.2006.2304 
[19] Richardson, C.A., Jull, G.A., Toppenberg, R. and Comerford, M. (1992) Techniques for Active Lumbar Stabilization for Spinal Protection: A Pilot Study. Australian Journal of Physiotherapy, 38, 105-112. https://doi.org/10.1016/S0004-9514(14)60555-9

[20] Kiesel, K.B., Uhl, T.L., Underwood, F.B., Rodd, D.W. and Nitz, A.J. (2007) Measurement of Lumbar Multifidus Muscle Contraction with Rehabilitative Ultrasound Imaging. Manual Therapy, 12, 161-166. https://doi.org/10.1016/j.math.2006.06.011

[21] Teyhen, D.S., Miltenberger, C.E., Deiters, H.M., et al. (2005) The Use of Ultrasound Imaging of the Abdominal Drawing-in Maneuver in Subjects With Low Back Pain. Journal of Orthopaedic \& Sports Physical Therapy, 35, 346-355. https://doi.org/10.2519/jospt.2005.35.6.346

[22] Lurie, J. and Tomkins-Lane, C. (2016) Management of Lumbar Spinal Stenosis. BMJ, 352, h6234. https://doi.org/10.1136/bmj.h6234

[23] Hodges, P.W. and Richardson, C.A. (1997) Feedforward Contraction of Transversus Abdominis Is Not Influenced by the Direction of Arm Movement. Experimental Brain Research, 114, 362-370. https://doi.org/10.1007/PL00005644

[24] Genevay, S. and Atlas, S.J. (2010) Lumbar Spinal Stenosis. Best Practice \& Research Clinical Rheumatology, 24, 253-265. https://doi:10.1016/j.berh.2009.11.001

Submit or recommend next manuscript to SCIRP and we will provide best service for you:

Accepting pre-submission inquiries through Email, Facebook, LinkedIn, Twitter, etc. A wide selection of journals (inclusive of 9 subjects, more than 200 journals)

Providing 24-hour high-quality service

User-friendly online submission system

Fair and swift peer-review system

Efficient typesetting and proofreading procedure

Display of the result of downloads and visits, as well as the number of cited articles

Maximum dissemination of your research work

Submit your manuscript at: http://papersubmission.scirp.org/

Or contact ojtr@scirp.org 